\title{
Characteristics of 2 Different Commercially Available Implants with or without Nanotopography
}

\author{
Ali Alenezi, ${ }^{1}$ Yoshihito Naito, ${ }^{1,2}$ Martin Andersson, ${ }^{3}$ Bruno R. Chrcanovic, ${ }^{1}$ \\ Ann Wennerberg, ${ }^{1}$ and Ryo Jimbo ${ }^{1}$ \\ ${ }^{1}$ Department of Prosthodontics, Faculty of Odontology, Malmö University, 20506 Malmö, Sweden \\ ${ }^{2}$ Department of Oral and Maxillofacial Prosthodontics and Oral Implantology, Institute of Health Biosciences, \\ The University of Tokushima Graduate School, 3-18-15 Kuramotocho, Tokushima 770-8504, Japan \\ ${ }^{3}$ Department of Chemical and Biological Engineering, Applied Surface Chemistry, Chalmers University of Technology, \\ 41296 Gothenburg, Sweden
}

Correspondence should be addressed to Ali Alenezi; ali.alenezi@mah.se

Received 12 June 2013; Accepted 21 July 2013

Academic Editor: Stefan Vandeweghe

Copyright (C) 2013 Ali Alenezi et al. This is an open access article distributed under the Creative Commons Attribution License, which permits unrestricted use, distribution, and reproduction in any medium, provided the original work is properly cited.

\begin{abstract}
The aim of this study was to assess histologically and histomorphometrically the early bone forming properties after 3 weeks for 2 commercially available implants, one supposedly possessing nanotopography and one without, in a rabbit femur model. Twentyfour implants divided equally into 2 groups were utilized in this study. The first group (P-I MICRO+NANO) was a titanium oxide $\left(\mathrm{TiO}_{2}\right)$ microblasted and noble gas ion bombarded surface while the second group (Ospol) was anodic oxidized surface with calcium and phosphate incorporation. The implants were placed in the rabbit femur unicortically and were allowed to heal for 3 weeks. After euthanasia, the samples were subjected to histologic sectioning and bone-implant contact and bone area were evaluated histomorphometrically under an optical microscope. The histomorphometric evaluation presented that the P-I MICRO+NANO implants demonstrated significantly higher new bone formation as compared to the Ospol implants. Within the limitations of this study, the results suggested that nanostructures presented significantly higher bone formation after 3 weeks in vivo, and the effect of chemistry was limited, which is indicative that nanotopography is effective at early healing periods.
\end{abstract}

\section{Introduction}

Replacing a missing tooth with endosseous implants has been recognized as a long-term successful treatment option $[1,2]$. Recent research trends further focus on enhancing the bone in apposition to the implant to ensure rapid and firm osseointegration. The major factors influencing the bone response around implants are reported to be the implant macrodesign, surface topography, and surface chemistry, which have been investigated in numerous studies [3-5]. Surface topography in particular has drawn significant attention as an important factor since it has been suggested that moderately rough implant surfaces present the strongest bone responses [68]. Alteration of the surface topography can be conducted in various methods, which provide unique characteristics [9]. Roughening the surface with blasting particles along with different types of acid etching is a commonly utilized technique to modify the surface topography $[10,11]$. This method is unique in a way that the roughness can be altered in a controlled manner by changing the velocity, particle size, and particle properties [12]. Furthermore, the acid etching not only cleans off the remnants of the particles, but creates a unique surface topography, which has also been reported to alter the surface chemistry $[13,14]$. It has been presented in numerous in vivo studies that this type of modification can enhance bone regeneration which is believed to be due increase in the surface area gained by surface roughness $[10,15-17]$. With regards to the effect of chemistry, it has been reported that elements such as calcium and phosphate have significant influence on bone formation $[18,19]$. It has also been reported that chemically modified surfaces provide a specific bonding between the implant and the surface, which has been described as biochemical bonding [20,21]. One of the recognized methods to chemically modify the 
surface is the anodic oxidation technique. It is a method to increase the thickness of the oxide layer with a possibility to incorporate elements such as magnesium and phosphates and also provide a unique porous topography [20-23]. It has been proven that this modification significantly improves both the rate and quality of osseointegration [20].

In order to further enhance osseointegration, recent research has focused on modifying the topography at the nanolevel, since cells and proteins are reportedly interacting at this level $[24,25]$. Reports suggest that in vitro these features could modify cellular shape and influence the migration and differentiation of mesenchymal stem cells [24-30]. It has been reported in several studies that the application of nanostructures increases the bioactivity of the implant surface which leads to an enhanced bone apposition around implants [31-33].

Although both nanotopographical and chemical modifications have proven to be an enhancing factor for osseointegration, it is of great interest to observe the bone forming characteristics of commercially available implants possessing either one of the factors. In this study, two commercially available implants, one supposedly possessing intended nanostructures formed by a noble gas ion bombardment and another chemically modified implant with calcium incorporated anodic oxidation, were characterized by various methods. Thereafter, the two commercially available implants were placed in the rabbit femur to observe histologically and histomorphometrically the early bone forming properties of 3 weeks.

\section{Materials and Methods}

2.1. Implant Surface Preparation and Characterization. Twenty-four implants divided into 2 groups were used in this study. The first group $(n=12)$ was a titanium oxide $\left(\mathrm{TiO}_{2}\right)$ microblasted and noble gas ion bombarded surface (Functional hybrid implants, P-I MICRO+NANO, Zimmer Dental), with a diameter of $3.75 \mathrm{~mm}$ and length of $11.5 \mathrm{~mm}$.

The second group $(n=12)$ was an anodic oxidized surface with calcium and phosphate incorporation (Ospol surface, Ospol, Zimmer Dental), with a diameter of $3.9 \mathrm{~mm}$ and length of $8.0 \mathrm{~mm}$.

2.2. Interferometer. Topographical analyses at microlevel were performed with interferometry (MicroXAMPhaseShift, Tucson, AZ, USA). Following guidelines that were suggested by Wennerberg and Albrektsson [34], three implants from each group were examined in order to characterize the surface roughness. Each implant was examined at 9 different positions ( 3 top areas, 3 valley areas, and 3 flank areas). Parametric calculations were performed after errors of form and waviness were removed using a $50 \times$ $50 \mathrm{~mm}$ Gaussian filter. Data was collected from the following three-dimensional parameters: the arithmetic mean of the height variation from a mean plane, $\mathrm{Sa}(\mu \mathrm{m})$; the density of summits, Sds $\left(\mu \mathrm{m}^{-2}\right)$; and the developed surface area added by the roughness, $\operatorname{Sdr}(\%)$. (Measurement area: $200 \mu \mathrm{m} \times$ $250 \mu \mathrm{m}$.
The evaluation was performed with the Surfascan software, and the images were produced using MounatinsMap universal 6.2 software.

2.3. Atomic Force Microscopy. The topographies of P-I $\mathrm{MICRO}+\mathrm{NANO}$ and Ospol surfaces were characterized at nanolevel using atomic force microscopy (XE-100, Park systems). The analysis was performed in noncontact mode using silicon nitride probe with a nominal resonance frequency between 200 and $400 \mathrm{kHz}$ (ACTA-10, APPNANO, USA). For this test, discs with the same implant surface treatment were used ( 3 discs for each group). Measurements areas of $(10 \times$ $10)$ and $(1 \times 1)$ in three random positions were selected for each disc. The measurements were performed at a scan rate of $0.50 \mathrm{~Hz}$.

The raw data obtained from the topographical equipment were further processed to separate the form, waviness, and roughness from the original measurements. A Gaussian high, pass filter was used (25\% of surface area). The Gaussian filter is suitable for smoothing surfaces with rich features. The parameters used to calculate surface roughness were the same ones used with interferometer which are: Sa, Sds, and Sdr. Analysis and processing of the AFM images were performed with the MountiansMap Universal 6.2 software.

2.4. Scanning Electron Microscopy. The surface morphologies of 2 discs from each group were examined by scanning electron microscopy (SEM) using an LEO Ultra 55 FEG (Zeiss, Oberkochen, Germany) at an accelerating voltage of $5 \mathrm{kV}$. A secondary electron in-lens detector was used for visualization.

2.5. X-Ray Photoelectron Spectroscopy. The surface chemistry was investigated using X-ray photoelectron spectroscopy (XPS) utilizing a Kratos Axis Ultra XPS instrument equipped with a monochromatic $\mathrm{Al} \mathrm{K} \alpha \mathrm{X}$-ray source. Binding energies between 0 and $1100 \mathrm{eV}$ were monitored, $0.800 \mathrm{eV} /$ step and $50 \mathrm{~ms} / \mathrm{step}$, at a pass energy of $187.85 \mathrm{eV}(150 \mathrm{~W})$. One implant from each group was examined.

2.6. Animals and Surgery. The study was approved by the Malmö/Lund, Sweden, Regional Animal Ethical Committee. Twelve rabbits were included of mixed sexes with an average weight of approximately $4 \mathrm{~kg}$.

Before surgery, the animals were sedated by intramuscular injections of a mixture of $0.15 \mathrm{~mL} / \mathrm{kg}$ of medetomidine $(1 \mathrm{mg} / \mathrm{mL}$ Dormitor-Orion Pharma, Sollentuna, Sweden) and $0.35 \mathrm{~mL} / \mathrm{kg}$ of ketamine hydrochloride $(50 \mathrm{mg} / \mathrm{mL}$ Ketalar-Pfizer AB, Sollentuna, Sweden). The hind legs were shaved and disinfected with $70 \%$ ethanol and $70 \%$ chlorhexidine. Lidocaine hydrochloride (Xylocaine-AstraZeneca AB, Gothenburg, Sweden) was administrated as local anesthetic at each insertion site at a dose of $1 \mathrm{~mL}$. After osteotomy preparation following the manufacturers instructions, the implants were inserted in both sides of the femur. After the operation, buprenorphine hydrochloride $(0.5 \mathrm{~mL}$ TemgesicReckitt Benckiser, Slough, UK) was administered as an 


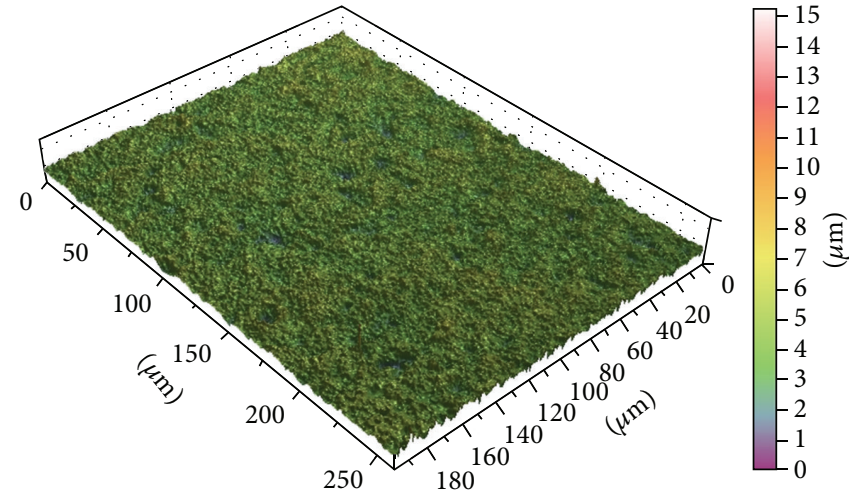

(a)

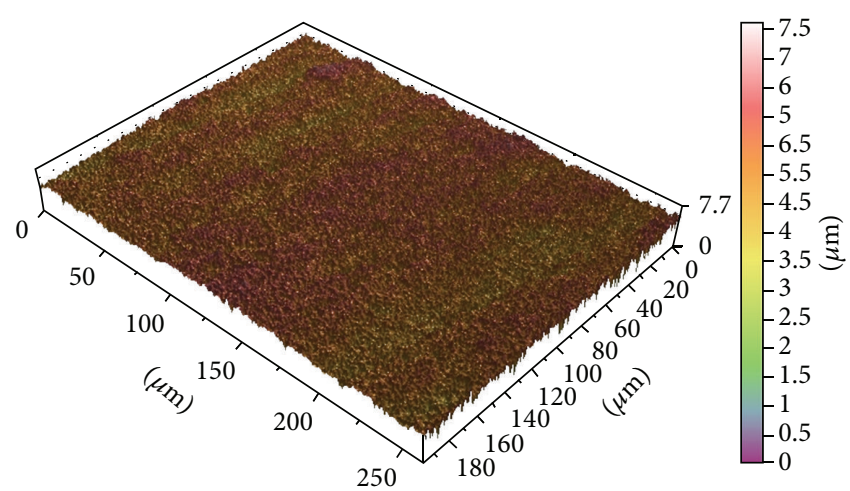

(b)

FIGURE 1: Representative interferometer images of 3D surface topography of the (a) P-I MICRO+NANO and (b) Ospol discs.

TABLE 1: Surface roughness measurements for implants of the two groups using interferometer ( 9 measurements/implant, $n=3$ ).

\begin{tabular}{lccc}
\hline Sample & Sa $\mu \mathrm{m}(\mathrm{SD})$ & $\mathrm{Sds} / \mathrm{mm}^{2}(\mathrm{SD})$ & Sdr \% (SD) \\
\hline P-I MICRO+NANO & $0.6070 \mu \mathrm{m}(0.075)$ & $186758 \mathrm{~mm}^{2}(20462)$ & $30.39 \%(8.45)$ \\
OSPOL & $0.3599 \mu \mathrm{m}(0.090)$ & $244573 \mathrm{~mm}^{2}(41090)$ & $44.08 \%(32.25)$ \\
\hline
\end{tabular}

TABLE 2: Surface roughness measurement using the AFM (scan size $10 \times 10$ ).

\begin{tabular}{lccc}
\hline Scan size $10 \times 10$ & Sa $\mu \mathrm{m}(\mathrm{SD})$ & $\mathrm{Sdr} \%(\mathrm{SD})$ & $\mathrm{Sds} 1 / \mu \mathrm{m}^{2}(\mathrm{SD})$ \\
\hline P-I MICRO+NANO & $0.051(0.007)$ & $8.49(3.59)$ & $9.59555(5.20)$ \\
OSPOL & $0.058(0.005)$ & $11.44(1.27)$ & $3.08(0.30)$ \\
\hline
\end{tabular}

analgesic for 3 days. After 3 weeks, the rabbits were euthanized with an overdose $(60 \mathrm{mg} / \mathrm{mL})$ of pentobarbital natrium (Apoteksbolaget AB, Stockholm, Sweden).

2.7. Histology and Histomorphometry. After euthanasia, the samples were processed in series of dehydrations in ethanol and infiltrations in resin; they were embedded in light-curing resin (Technovit 7200 VLC-Heraeus Kulzer, Wehrheim, Germany). Thereafter, the resin-embedded samples were subjected to undecalcified ground sectioning. One central ground section was prepared from each block by using the Exakt sawing and grinding equipment [35]. The sections were ground to a final thickness of approximately $20 \mu \mathrm{m}$ and histologically stained with toluidine blue and pyronin G.

Histological evaluations were performed using a light microscope (Eclipse ME600-Nikon Co., Tokyo, Japan), and the histomorphometrical data were analyzed by image analysis software (Image J v. 1.43u-National Institutes of Health, Bethesda, MD, USA). The bone-implant contact (BIC) percentage and the bone area (BA) and the new bone area (new$\mathrm{BA})$ percentages along the implant for total bone and new bone were calculated. New bone formation surrounding the implants was used for evaluating the osteoconductivity.

2.8. Statistical Analysis. For the histological evaluation, the wilcoxon rank-sum test was used for statistical analysis. For interferometer and AFM measurements, the mean values of surface roughness were compared with those of Independentsamples $t$-test using Statistical Package for the Social Sciences (SPSS) version 20 software (SPSS Inc., Chicago, USA). The degree of statistical significance was considered $P<0.05$.

\section{Results}

3.1. Topographical Characterization. The results of the interferometer measurements are presented in Table 1 . The average height deviation $(\mathrm{Sa})$ was significantly different between the two groups $(P=0.000)$. Both surfaces were smooth according to the definition by Albrektsson and Wennerberg [3].

Further, the number of summits per unit area (Sds) differed significantly among the surfaces, with the Ospol surface presenting higher values than the P-I MICRO+NANO surface $(P=0.000)$.

The surface enlargement percentage (Sdr) showed that the Ospol surface had a significantly larger surface area than the P-I MICRO+NANO surface $(P=0.028)$. Figure 1 shows Interferometer images of $3 \mathrm{D}$ surface topography of the P-I MICRO+NANO and Ospol discs.

In contrast to the interferometer analysis, high-resolution topographical analysis with the AFM showed decreased surface roughness for the P-I MICRO+NANO compared to Ospol discs. The Sa, Sds, and Sdr parameters of the two groups at $10 \times 10$ scan size are presented in Table 2 . The statistical analysis showed significant differences in Sdr and Sds values $(P=0.027$ and 0.002 , resp.). 
TABLE 3: Surface roughness measurement using the AFM (scan size $1 \times 1)$.

\begin{tabular}{lccc}
\hline Scan size $1 \times 1$ & Sa nm $(\mathrm{SD})$ & $\mathrm{Sdr} \%(\mathrm{SD})$ & $\mathrm{Sds} 1 / \mu \mathrm{m}^{2}(\mathrm{SD})$ \\
\hline P-I MICRO+NANO & $4.35(1.36)$ & $8.56(7)$ & $1533(671)$ \\
OSPOL & $5.18(1.11)$ & $8.9(3.70)$ & $2295.2(734)$ \\
\hline
\end{tabular}

TABLE 4: Surface chemical composition (atomic \%) using XPS.

\begin{tabular}{lccccrr}
\hline Element & C1s & N1s & O1s & P2p & Ca2p & Ti2p \\
\hline P-I MICRO+NANO & 22.75 & 1.07 & 56.77 & & 18.53 \\
OSPOL & 17.51 & 0.46 & 58.88 & 2.38 & 2.23 & 18.55 \\
\hline
\end{tabular}

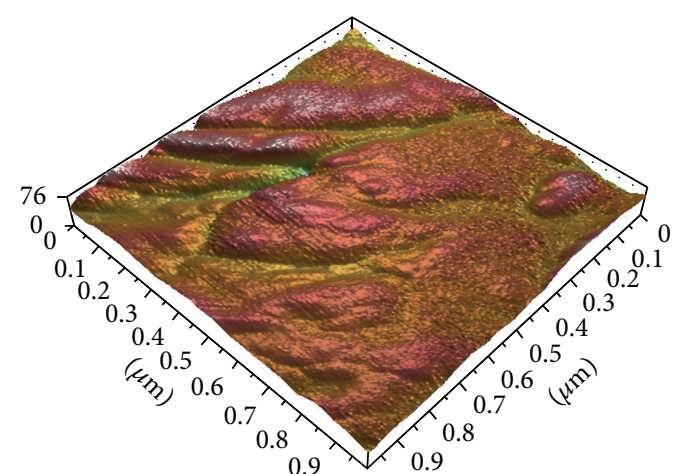

(a)

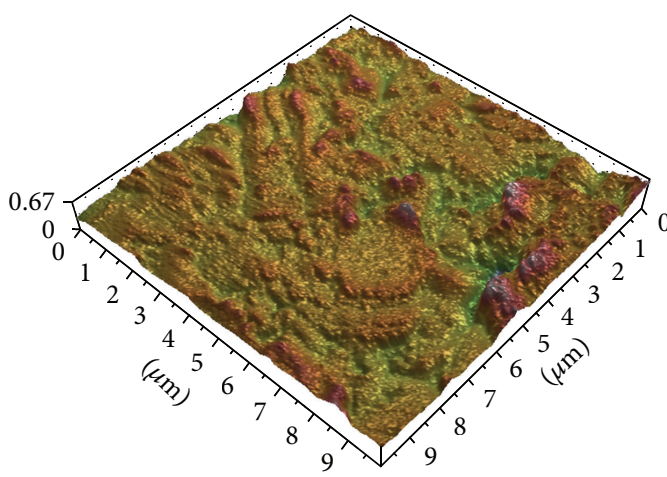

(c)

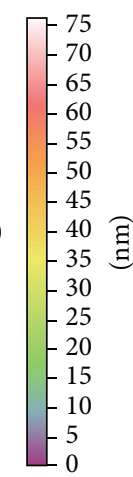

0.65
0.6
0.55
0.5
0.45
0.4
0.35
0.3
0.25
0.2
0.15
0.1
0.05
0 (1)

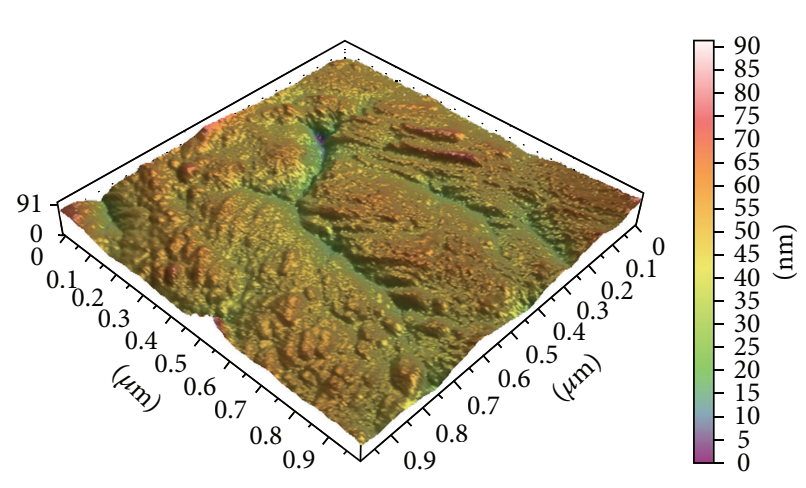

(b)

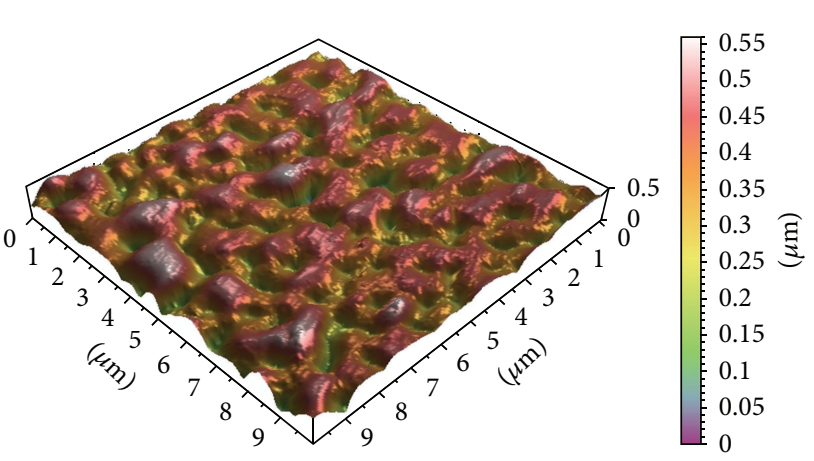

(d)

Figure 2: Representative AFM images of the 3D surface topography of (a) P-I MICRO+NANO, (b) Ospol discs at $1 \times 1$ scan area, (c) P-I MICRO+NANO, and (d) Ospol discs at $10 \times 10$ scan area.

For the $1 \times 1$ scan size, the Sa, Sds, and Sdr parameters are presented in Table 3 . The statistical analysis shows significant difference only in the Sds value $(P=0.035)$. Representative AFM images of the 3D surface topography of the P-I MICRO+NANO and Ospol discs for both scan ranges are presented in Figure 2.

3.2. Scanning Electron Microscopy. Scanning electron microscopy images of the P-I MICRO+NANO and Ospol discs are presented in Figure 3. At high magnification, P-I MICRO+NANO surface showed distinct, distributed, nanosized bumps with nanoparticles less than $100 \mathrm{~nm}$ in size. Ospol surface on the other hand showed extremely smooth surface with porous structures distributed on the surface with a diameter of approximately $300-500 \mathrm{~nm}$.
3.3. X-Ray Photoelectron Spectroscopy. XPS survey spectra for the P-I MICRO+NANO and Ospol implants are presented in Figure 4, and the surface chemical composition is presented in Table 4. As it can be seen in the table, the largest difference between the two surfaces is the presence of calcium and phosphate on the Ospol surface. However, a relatively small amount of calcium was observed also on the P-I MICRO+NANO surface. Carbon and small quantities of nitrogen were present on both implants, which most probably is due to contamination.

3.4. Histology and Histomorphometry. A descriptive histologic image for both groups is presented in Figure 5. In brief, deeply stained woven bone was formed along the implant, 
TABLE 5: Summary of the histomorphometric measurements.

\begin{tabular}{|c|c|c|c|c|c|c|}
\hline Group & $\begin{array}{c}\text { BIC \% } \\
\text { (All threads) } \\
\text { (SD) }\end{array}$ & $\begin{array}{c}\text { BIC } \% \\
\text { (Top } 3 \text { threads) } \\
(\mathrm{SD})\end{array}$ & $\begin{array}{c}\text { BA \% } \\
\text { (All threads) } \\
(\mathrm{SD})\end{array}$ & $\begin{array}{c}\text { BA \% } \\
\text { (Top } 3 \text { threads) } \\
(\mathrm{SD})\end{array}$ & $\begin{array}{c}\text { New BA \% } \\
\text { (All threads) } \\
(\mathrm{SD})\end{array}$ & $\begin{array}{c}\text { New BA \% } \\
\text { (Top } 3 \text { threads) } \\
(\mathrm{SD})\end{array}$ \\
\hline P-I MICRO+NANO & $54.33(14.7)$ & $59.25(12.9)$ & $54.75(8.4)$ & $57.166(10.1)$ & $46.416(9.4)$ & $47.25(10.15)$ \\
\hline OSPOL & $52.75(15)$ & $58.08(14.7)$ & $52.41(13.8)$ & $59.083(13.9)$ & $35.83(10.6)$ & $36.416(11.3)$ \\
\hline
\end{tabular}

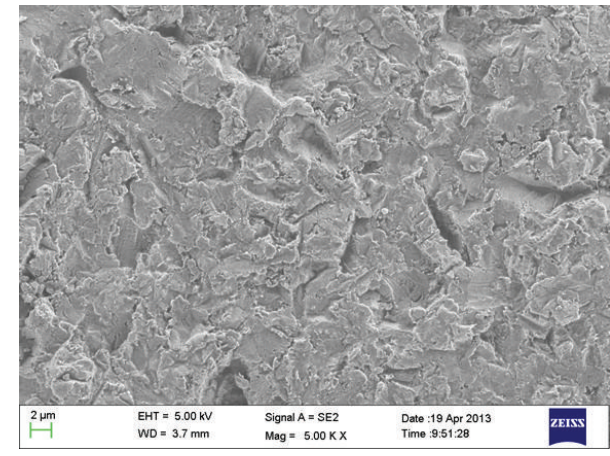

(a)

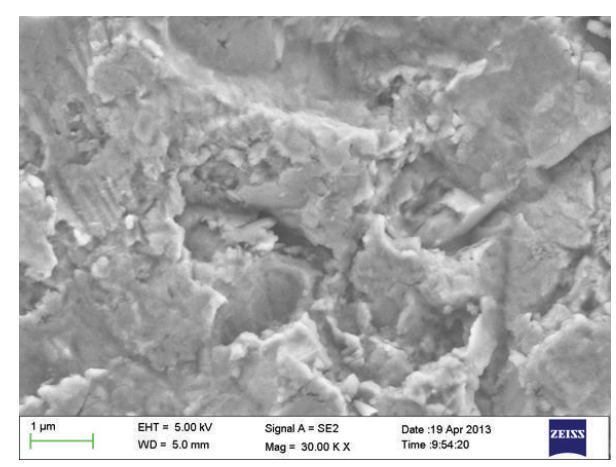

(c)

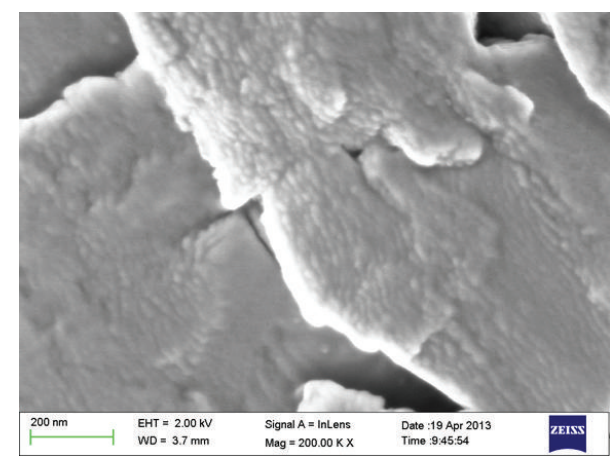

(e)

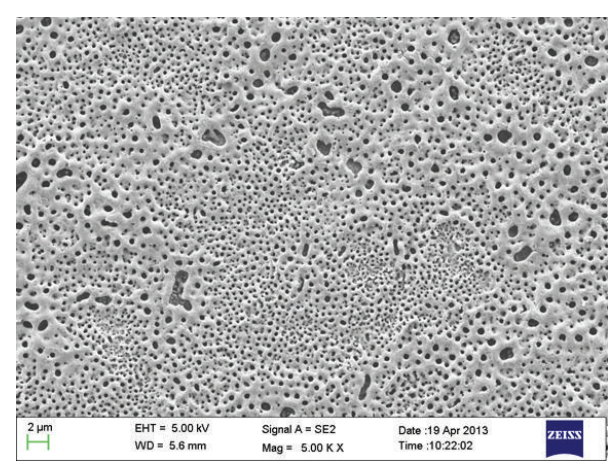

(b)

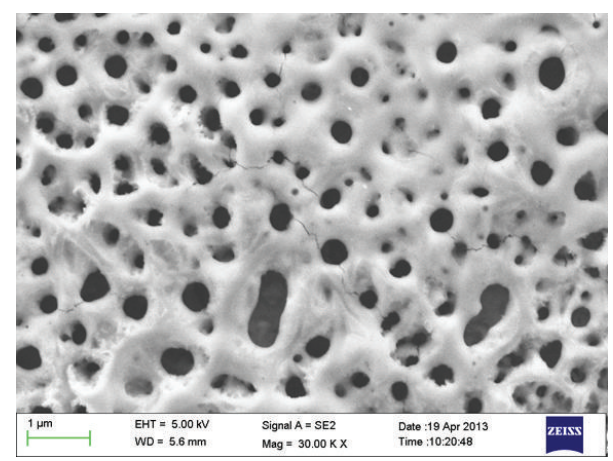

(d)

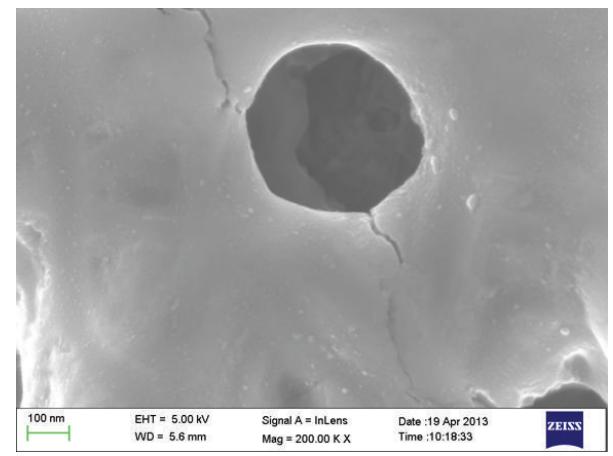

(f)

FIGURE 3: SEM images for the discs surfaces show (a) P-I MICRO+NANO and (b) Ospol at 5Kx magnification, (c) P-I MICRO+NANO and (d) Ospol at 30Kx magnification and (e) P-I MICRO+NANO and (f) Ospol at 200Kx magnification.

which was in close contact for both groups. No signs of inflammation or bone resorption were evident.

The mean BIC values for all implant threads and for the top 3 threads of P-I MICRO+NANO and Ospol implants demonstrated no significant differences $(P=0.906, P=0.87$, resp.). When measuring the osteoconductivity of the surfaces, the two groups did not differ in BA\% for both all threads and top 3 threads $(P=0.624, P=0.583$, resp. $)$.

The new bone formation presented that the P-I MICRO+NANO implants which had significantly higher new bone are between all threads and the top 3 threads $(P=0.034, P=0.025$, resp. $)$. Table 5 summarizes all 


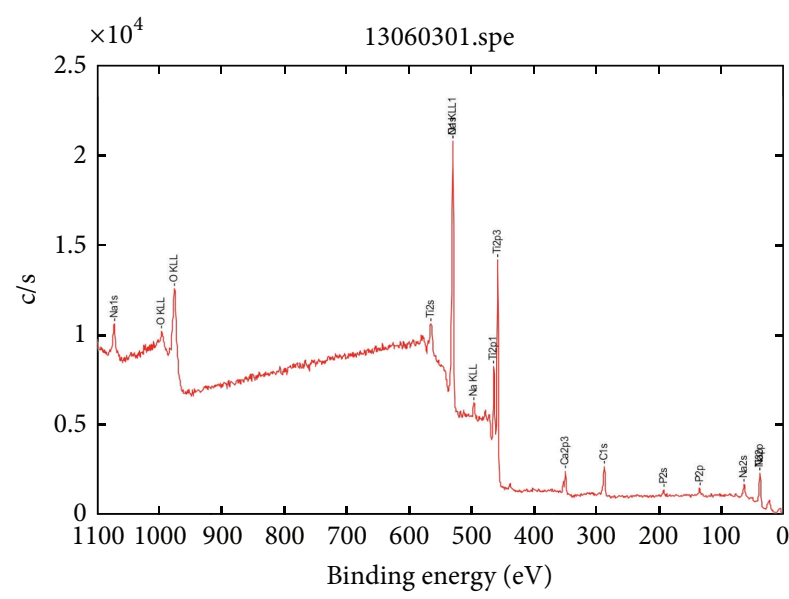

(a)

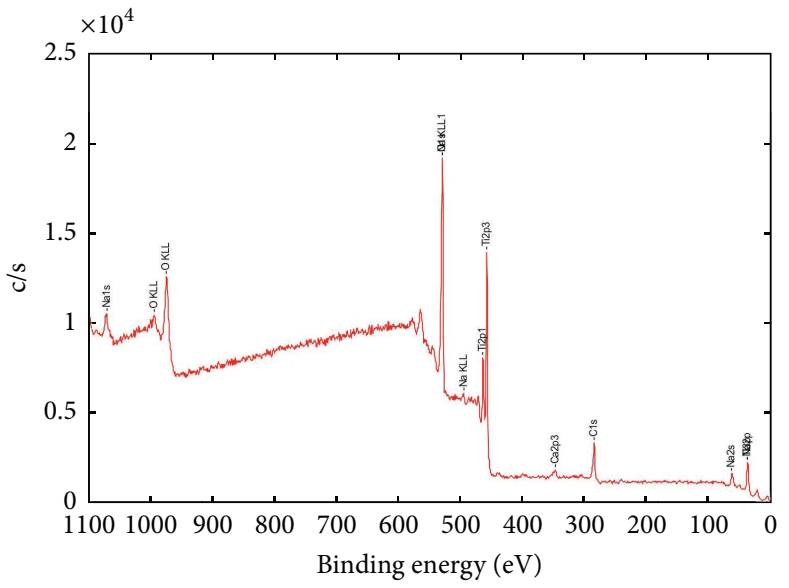

(b)

FIgURE 4: XPS survey spectra (a) Ospol and (b) P-I MICRO+NANO implants.

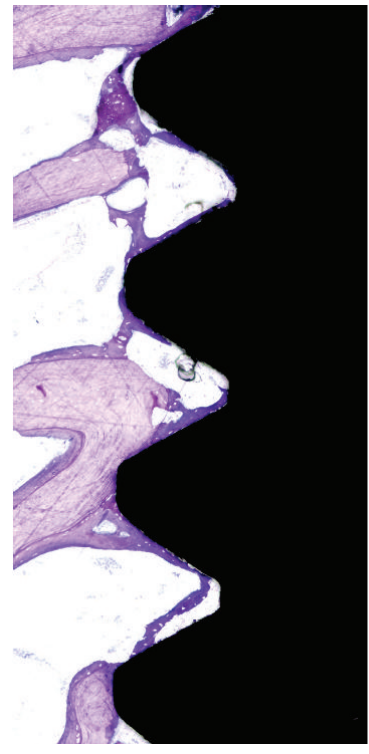

(a)

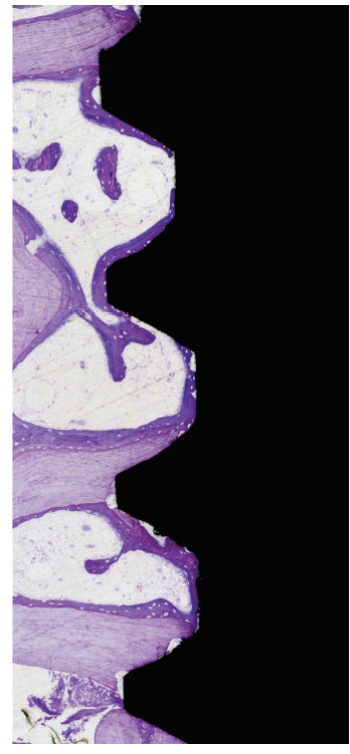

(b)
Figure 5: Histological observations of P-IMICRO+NANO implant (a) and Ospol implant (b) after 3 weeks (toluidine blue and pyronin staining, original magnification $\times 10$ ). Cortical old bone is visualized in pale red while the New Bone is visualized in dark red.

histomorphometric measurements. Figure 6 shows a descriptive histological image for new bone formation in P-I MICRO+NANO implants after 3 weeks.

\section{Discussion}

In the present study, 2 commercially available implants with and without nanostructures were chemically and topographically characterized, and the bone forming properties were evaluated after 3 weeks in vivo in a rabbit femur model.

From the SEM observations, the Ospol surface presented an extremely smooth morphology, and nanostructures in size

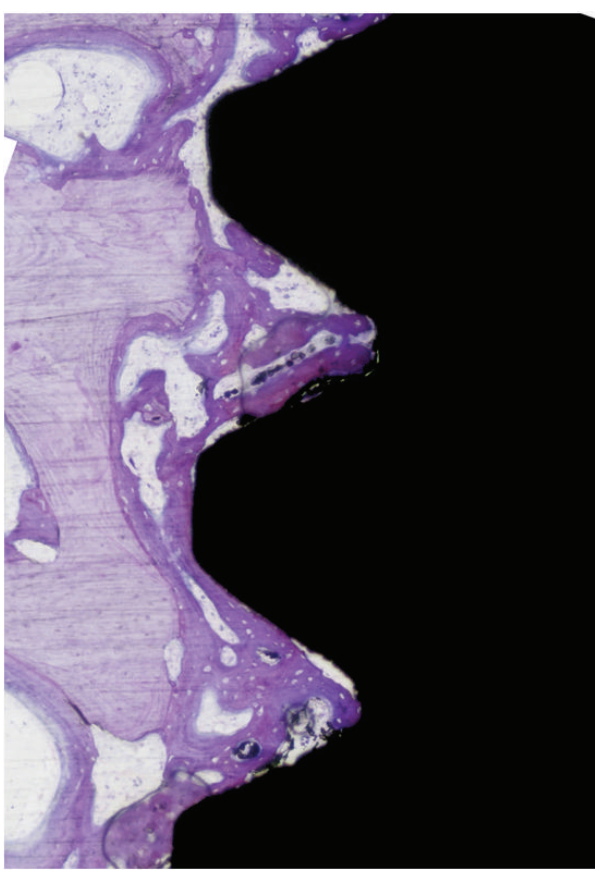

FIGURE 6: Histological observations of new bone formation among the threads of P-I MICRO+NANO implant after 3 weeks (toluidine blue and pyronin staining, original magnification $\times 10$ ). Cortical old bone is visualized in pale red while the New Bone is visualized in dark red.

of $100 \mathrm{~nm}$ or less could not be seen. The anodic oxidation process of the surface showed a typical surface morphology with porous structures of $300-500 \mathrm{~nm}$ in size. On the other hand, the SEM images for the P-I MICRO+NANO surface presented a typical surface morphology as a result of the $\mathrm{TiO}_{2}$ particle blasting with homogeneous nanostructures of about $20 \mathrm{~nm}$ in diameter.

The surface topography in the microlevel confirmed by the interferometer presented unique differences for both surfaces. It was confirmed that both surfaces were smooth 
according to the report from Wennerberg and Albrektsson [36]. The average height deviation (Sa) was significantly higher for the P-I MICRO+NANO surface, probably due to the topography created by the surface roughening procedure. However, the density of summits (Sds) and surface enlargement ratio (Sdr) were significantly higher for the Ospol, probably due to the existence of porous structures. The evaluation in the nanolevel confirmed by the AFM presented that the Sds was significantly higher for the P-I MICRO+NANO, which is an indication that the surface has been roughened in the nanoscale. The investigation of the chemical composition of the 2 different surfaces presented that the P-I MICRO+NANO surface presented a high amount of $\mathrm{TiO}_{2}$ due to the surface blasting procedure and the Ospol surface had large amounts of $\mathrm{Ca}$ and $\mathrm{P}$ on its surface, probably due to the anodic oxidation procedure performed in baths with these elements.

The histomorphometric measurements presented no significant differences in BIC or in total BA. However, when analyzing the amount of new bone formation represented by deeply stained tissue, significantly higher percentage in favor of the P-I MICRO+NANO implant was shown. The results strongly suggest that both surfaces have abundant osseointegration properties. This was evident in the representative histologic micrographs, where newly formed bone extended from the trabecular bone almost encapsulated the implant surface. The fact that the P-I MICRO+NANO surface presented higher new bone formation within the implant chamber is an indication that the slightly, but significantly, higher microtopography and the presence of the homogeneous nanotopography had positive effects on the bone. Although the Ospol surface underwent a chemical modification incorporating $\mathrm{Ca}$ and $\mathrm{P}$ into the surface, the histomorphometric results indicated that the chemical modification did not seem to have a strong influence on bone regeneration and the effect of topography was more significant. It is difficult to draw conclusions whether the topography or the chemistry plays a decisive role on bone formation, since some studies suggest the effect of nanotopography to be an influential factor $[37,38]$ and some others suggest that the effect of chemistry is of most importance $[39,40]$. However, in cases where the nanostructure itself is consisting from $\mathrm{CaP}$, it seems that there is a synergistic effect, with the bone mineralization properties being significantly enhanced [32, 41, 42]. It can be said that both chemical and topographical modifications are of great importance for osseointegration; however, their biologic effects may be dependent on numerous factors. More studies are necessary to determine the optimal surface that would present the strongest bone responses, and longer time points are warranted to observe the effect during longer healing periods.

\section{Conclusion}

The results suggested that the effect of homogenous nanostructures presented significantly higher bone formation after 3 weeks in vivo, which suggests the effect of nanotopography at early healing periods.

\section{Conflict of Interests}

The authors report no conflicts of interests.

\section{References}

[1] R. Adell, U. Lekholm, B. Rockler, and P. I. Branemark, "A 15year study of osseointegrated implants in the treatment of the edentulous jaw," International Journal of Oral Surgery, vol. 10, no. 6, pp. 387-416, 1981.

[2] M. Esposito, J.-M. Hirsch, U. Lekholm, and P. Thomsen, "Biological factors contributing to failures of osseointegrated oral implants. (I). Success criteria and epidemiology," European Journal of Oral Sciences, vol. 106, no. 1, pp. 527-551, 1998.

[3] T. Albrektsson and A. Wennerberg, "Oral implant surfaces: part 1-review focusing on topographic and chemical properties of different surfaces and in vivo responses to them," International Journal of Prosthodontics, vol. 17, no. 5, pp. 536-543, 2004.

[4] A. A. Balshe, D. A. Assad, S. E. Eckert, S. Koka, and A. L. Weaver, "A retrospective study of the survival of smooth- and roughsurface dental implants," The International Journal of Oral \& Maxillofacial Implants, vol. 24, no. 6, pp. 1113-1118, 2009.

[5] A. Rocci, M. Martignoni, and J. Gottlow, "Immediate loading of Branemark System TiUnite and machined-surface implants in the posterior mandible: a randomized open-ended clinical trial," Clinical Implant Dentistry and Related Research, vol. 5, supplement 1, pp. 57-63, 2003.

[6] A. Wennerberg, T. Albrektsson, B. Andersson, and J. J. Krol, "A histomorphometric and removal torque study of screw-shaped titanium implants with three different surface topographies," Clinical Oral Implants Research, vol. 6, no. 1, pp. 24-30, 1995.

[7] A. Wennerberg, T. Albrektsson, and B. Andersson, "Bone tissue response to commercially pure titanium implants blasted with fine and coarse particles of aluminum oxide," International Journal of Oral and Maxillofacial Implants, vol. 11, no. 1, pp. 3845, 1996.

[8] A. Wennerberg, T. Albrektsson, and J. Lausmaa, “Torque and histomorphometric evaluation of c.p. titanium screws blasted with 25- and 75-microns-sized particles of $\mathrm{Al}_{2} \mathrm{O}_{3}$," Journal of Biomedical Materials Research, vol. 30, no. 2, pp. 251-260, 1996.

[9] L. Le Guéhennec, A. Soueidan, P. Layrolle, and Y. Amouriq, "Surface treatments of titanium dental implants for rapid osseointegration," Dental Materials, vol. 23, no. 7, pp. 844-854, 2007.

[10] D. Buser, N. Broggini, M. Wieland et al., "Enhanced bone apposition to a chemically modified SLA titanium surface," Journal of Dental Research, vol. 83, no. 7, pp. 529-533, 2004.

[11] D. Buser, T. Nydegger, T. Oxland et al., "Interface shear strength of titanium implants with a sandblasted and acid-etched surface: a biomechanical study in the maxilla of miniature pigs," Journal of Biomedical Materials Research, vol. 45, no. 2, pp. 7583, 1999.

[12] G. B. Valverde, R. Jimbo, H. S. Teixeira, E. A. Bonfante, M. N. Janal, and P. G. Coelho, "Evaluation of surface roughness as a function of multiple blasting processing variables," Clinical Oral Implants Research, vol. 24, no. 2, pp. 238-242, 2013.

[13] B.-S. Kang, Y.-T. Sul, S.-J. Oh, H.-J. Lee, and T. Albrektsson, "XPS, AES and SEM analysis of recent dental implants," Acta Biomaterialia, vol. 5, no. 6, pp. 2222-2229, 2009.

[14] S. Valencia, C. Gretzer, and L. R. Cooper, "Surface nanofeature effects on titanium-adherent human mesenchymal stem cells," 
International Journal of Oral and Maxillofacial Implants, vol. 24, no. 1, pp. 38-46, 2009.

[15] K. Gotfredsen, A. Wennerberg, C. Johansson, L. T. Skovgaard, and E. Hjorting-Hansen, "Anchorage of $\mathrm{TiO}_{2}$-blasted, HAcoated, and machined implants: an experimental study with rabbits," Journal of Biomedical Materials Research, vol. 29, no. 10, pp. 1223-1231, 1995.

[16] Y. Germanier, S. Tosatti, N. Broggini, M. Textor, and D. Buser, "Enhanced bone apposition around biofunctionalized sandblasted and acid-etched titanium implant surfaces: a histomorphometric study in miniature pigs," Clinical Oral Implants Research, vol. 17, no. 3, pp. 251-257, 2006.

[17] C. Marin, R. Granato, M. Suzuki, J. N. Gil, A. Piattelli, and P. G. Coelho, "Removal torque and histomorphometric evaluation of bioceramic grit-blasted/acid-etched and dual acid-etched implant surfaces: an experimental study in dogs," Journal of Periodontology, vol. 79, no. 10, pp. 1942-1949, 2008.

[18] V. C. Mendes, R. Moineddin, and J. E. Davies, "Discrete calcium phosphate nanocrystalline deposition enhances osteoconduction on titanium-based implant surfaces," Journal of Biomedical Materials Research A, vol. 90, no. 2, pp. 577-585, 2009.

[19] R. Jimbo, T. Sawase, Y. Shibata et al., "Enhanced osseointegration by the chemotactic activity of plasma fibronectin for cellular fibronectin positive cells," Biomaterials, vol. 28, no. 24, pp. 3469-3477, 2007.

[20] Y.-T. Sul, E.-S. Byon, and Y. Jeong, "Biomechanical measurements of calcium-incorporated oxidized implants in rabbit bone: effect of calcium surface chemistry of a novel implant," Clinical Implant Dentistry and Related Research, vol. 6, no. 2, pp. 101-110, 2004.

[21] Y.-T. Sul, C. Johansson, A. Wennerberg, L.-R. Cho, B.-S. Chang, and T. Albrektsson, "Optimum surface properties of oxidized implants for reinforcement of osseointegration: surface chemistry, oxide thickness, porosity, roughness, and crystal structure," International Journal of Oral and Maxillofacial Implants, vol. 20, no. 3, pp. 349-359, 2005.

[22] Y.-T. Sul, J. Jönsson, G.-S. Yoon, and C. Johansson, "Resonance frequency measurements in vivo and related surface properties of magnesium-incorporated, micropatterned and magnesiumincorporated TiUnite, Osseotite, SLA and TiOblast implants," Clinical Oral Implants Research, vol. 20, no. 10, pp. 1146-1155, 2009.

[23] Y. T. Sul et al., "Oxidized implants and their influence on the bone response," Journal of Materials Science, vol. 12, no. 10-12, pp. 1025-1031, 2001.

[24] L. Ferreira, J. M. Karp, L. Nobre, and R. Langer, "New opportunities: the use of nanotechnologies to manipulate and track stem cells," Cell Stem Cell, vol. 3, no. 2, pp. 136-146, 2008.

[25] T. J. Webster and J. U. Ejiofor, "Increased osteoblast adhesion on nanophase metals: Ti, Ti6Al4V, and CoCrMo," Biomaterials, vol. 25, no. 19, pp. 4731-4739, 2004.

[26] S. Lavenus, G. Louarn, and P. Layrolle, "Nanotechnology and dental implants," International Journal of Biomaterials, vol. 2010, Article ID 915327, 9 pages, 2010.

[27] F. Variola, J.-H. Yi, L. Richert, J. D. Wuest, F. Rosei, and A. Nanci, "Tailoring the surface properties of Ti6Al4V by controlled chemical oxidation," Biomaterials, vol. 29, no. 10, pp. 1285-1298, 2008.

[28] T. J. Webster, R. W. Siegel, and R. Bizios, "Osteoblast adhesion on nanophase ceramics," Biomaterials, vol. 20, no. 13, pp. 12211227, 1999.
[29] T. J. Webster, C. Ergun, R. H. Doremus, R. W. Siegel, and R. Bizios, "Enhanced functions of osteoblasts on nanophase ceramics," Biomaterials, vol. 21, no. 17, pp. 1803-1810, 2000.

[30] M. J. Dalby, A. Andar, A. Nag et al., "Genomic expression of mesenchymal stem cells to altered nanoscale topographies," Journal of the Royal Society Interface, vol. 5, no. 26, pp. 10551065, 2008.

[31] D. M. D. Ehrenfest, P. G. Coelho, B.-S. Kang, Y.-T. Sul, and T. Albrektsson, "Classification of osseointegrated implant surfaces: materials, chemistry and topography," Trends in Biotechnology, vol. 28, no. 4, pp. 198-206, 2010.

[32] R. Jimbo, J. Sotres, C. Johansson, K. Breding, F. Currie, and A. Wennerberg, "The biological response to three different nanostructures applied on smooth implant surfaces," Clinical Oral Implants Research, vol. 23, no. 6, pp. 706-712, 2012.

[33] L. M. Bjursten, L. Rasmusson, S. Oh, G. C. Smith, K. S. Brammer, and S. Jin, "Titanium dioxide nanotubes enhance bone bonding in vivo," Journal of Biomedical Materials Research A, vol. 92, no. 3, pp. 1218-1224, 2010.

[34] A. Wennerberg and T. Albrektsson, "Suggested guidelines for the topographic evaluation of implant surfaces," International Journal of Oral and Maxillofacial Implants, vol. 15, no. 3, pp. 331$344,2000$.

[35] K. Donath and G. Breuner, "A method for the study of undecalcified bones and teeth with attached soft tissues. The Sage-Schliff (sawing and grinding) technique," Journal of Oral Pathology, vol. 11, no. 4, pp. 318-326, 1982.

[36] A. Wennerberg and T. Albrektsson, "On implant surfaces: a review of current knowledge and opinions," The International Journal of Oral \& Maxillofacial Implants, vol. 25, no. 1, pp. 6374, 2010.

[37] L. Meirelles, A. Arvidsson, T. Albrektsson, and A. Wennerberg, "Increased bone formation to unstable nano rough titanium implants," Clinical Oral Implants Research, vol. 18, no. 3, pp. 326332, 2007.

[38] J. Karlsson, R. Jimbo, H. M. Fathali et al., "In vivo biomechanical stability of osseointegrating mesoporous $\mathrm{TiO}_{2}$ implants," Acta Biomater, vol. 8, no. 12, pp. 4438-4446, 2012.

[39] Y.-T. Sul, D. H. Kwon, B.-S. Kang, S.-J. Oh, and C. Johansson, "Experimental evidence for interfacial biochemical bonding in osseointegrated titanium implants," Clinical Oral Implants Research, vol. 24, supplement A100, pp. 8-19, 2011.

[40] Y.-T. Sul, C. Johansson, and T. Albrektsson, "A novel in vivo method for quantifying the interfacial biochemical bond strength of bone implants," Journal of the Royal Society Interface, vol. 7, no. 42, pp. 81-90, 2009.

[41] R. Jimbo, P. G. Coelho, M. Bryington et al., "Nano hydroxyapatite-coated implants improve bone nanomechanical properties," Journal of Dental Research, vol. 91, no. 12, pp. 11721177, 2012.

[42] R. Jimbo, P. G. Coelho, S. Vandeweghe et al., "Histological and three-dimensional evaluation of osseointegration to nanostructured calcium phosphate-coated implants," Acta Biomaterialia, vol. 7, no. 12, pp. 4229-4234, 2011. 


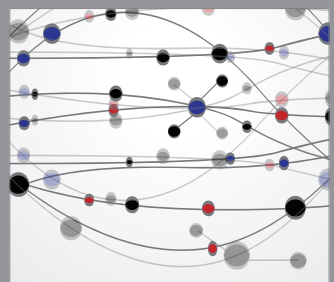

The Scientific World Journal
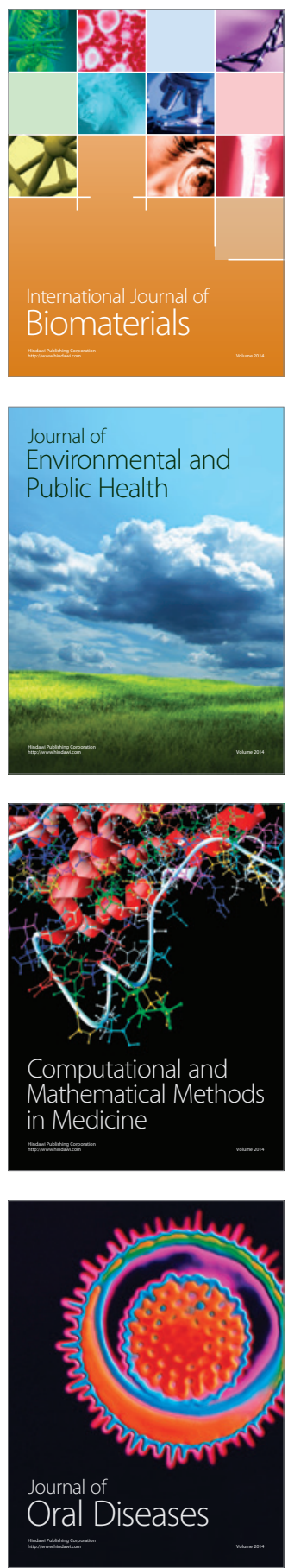
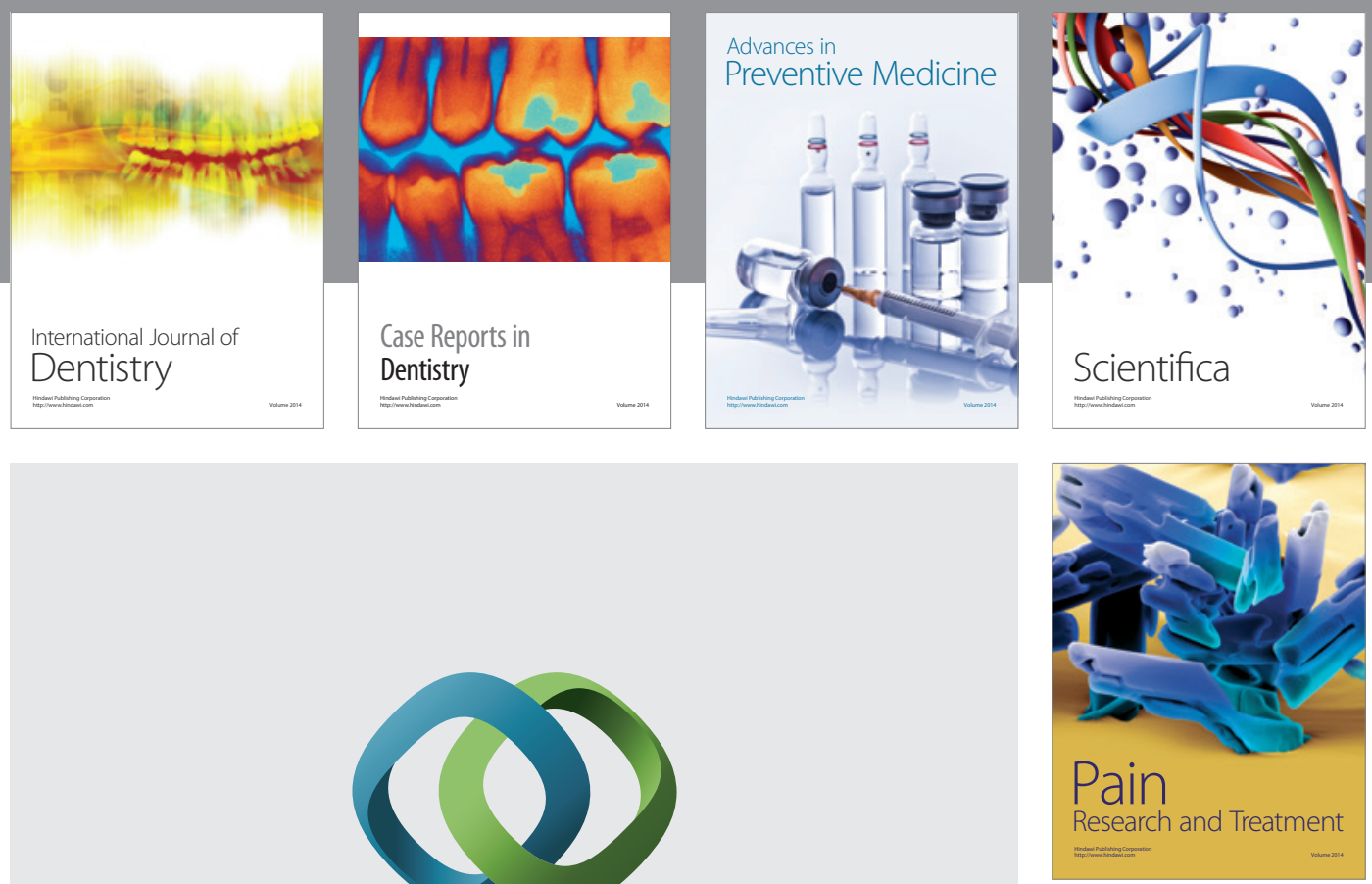

\section{Hindawi}

Submit your manuscripts at

http://www.hindawi.com
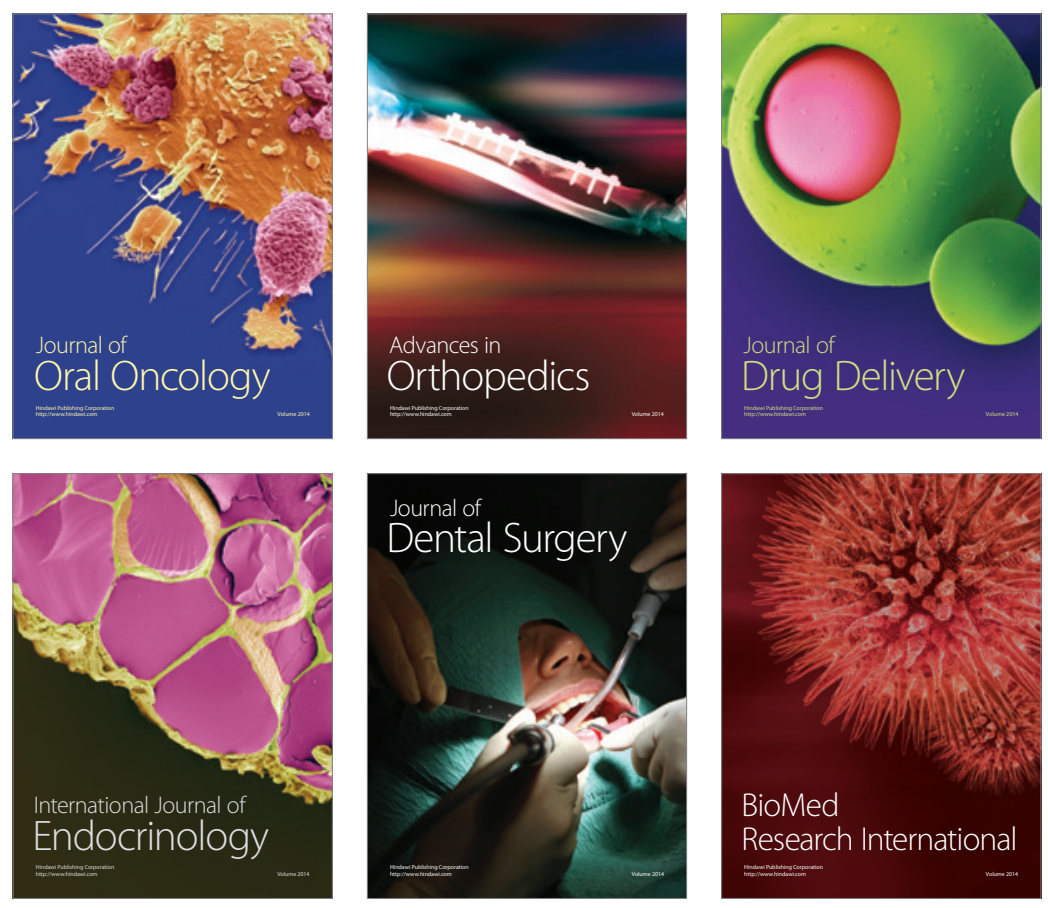

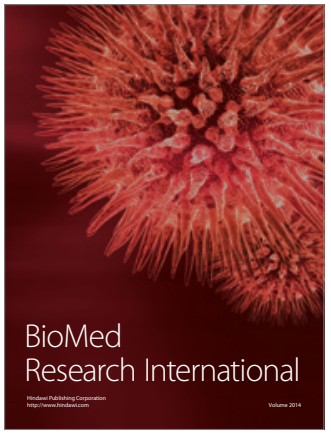

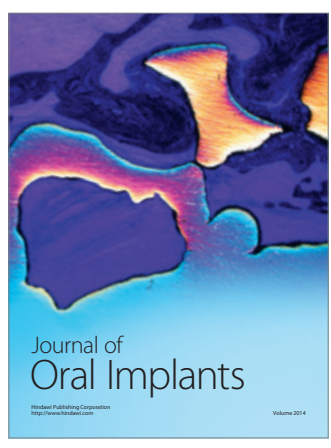
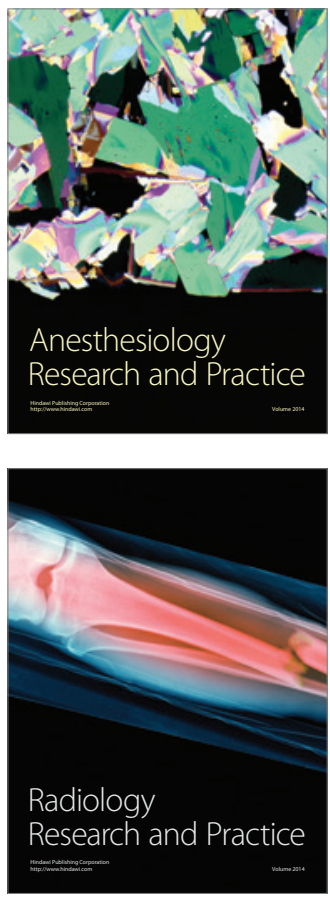